\title{
PENGEMBANGAN INSTRUMEN NIAT TECHNOPRENEURSHIP DI SEKOLAH MENENGAH KEJURUAN
}

\author{
Amelia Fauziah Husna ${ }^{1}$, Herminarto Sofyan ${ }^{2}$ \\ ${ }^{1}$ Jurusan Pendidikan Teknik Elektro FT UNY; ${ }^{2}$ Program Studi Pendidikan Teknologi dan Kejuruan PPs UNY \\ email : amelia.husna@uny.ac.id
}

\begin{abstract}
The purposes of this study were to determine the value of the validity and reliability of the indicators that make up the intention of technopreneurship in Vocational School. The results show that there are 3 indicators that compose intention of technopreneurship, there are attitudes toward behavior, subjective norms, and perceived behavioral control. Attitudes toward behavior are supported by affective and instrumental attitudes. Subjective norms are supported by descriptive and injuctive norms. Perceived behavioral control is supported by self-efficacy, control belief, and strong perception. The intention of technopreneurship has 15 items that can be categorized as valid and reliable.
\end{abstract}

Keywords: intention of technopreneurship, reliability, validity, Vocational School

\begin{abstract}
ABSTRAK
Tujuan penelitian ini adalah untuk mengetahui nilai validitas dan reliabilitas indikator yang menyusun niat technopreneurship di SMK. Hasil penelitian menunjukkan bahwa terdapat 3 indikator yang menyusun niat technopreneurship, yaitu sikap terhadap perilaku, norma subyektif, dan persepsi kontrol perilaku. Sikap terhadap perilaku didukung faktor sikap afektif dan sikap instrumental. Norma subyektif didukung oleh norma deskriptif dan norma injuktif. Persepsi kontrol perilaku didukung oleh efikasi diri, kontrol keyakinan, dan kuat persepsi. Niat technopreneurship memiliki 15 butir penilaian yang dapat dikategorikan valid dan reliabel.
\end{abstract}

Kata kunci: niat technopreneurship, reliabilitas, SMK, validitas

\section{PENDAHULUAN}

Sekolah Menengah Kejuruan (SMK) menjadi salah satu penyedia lulusan yang memiliki keterampilan khusus sesuai dengan kebutuhan di pasar kerja (Direktorat Pembinaan SMK, 2017). Tenaga kerja yang diluluskan SMK seharusnya memiliki kategori skilled labor sesuai dengan tuntutan industri. SMK yang saat ini tersedia memang banyak, namun menimbulkan masalah baru. Masalah tersebut adalah adanya pengangguran terbuka yang merupakan lulusan SMK.

Lulusan SMK memiliki jumlah pengangguran lebih banyak daripada Sekolah
Menengah Atas (SMA). SMA sendiri merupakan sekolah yang meluluskan peserta didiknya tanpa keterampilan khusus, sehingga perlu melanjutkan ke jenjang selanjutnya untuk mendapat keterampilan tertentu. November 2019, Badan Pusat Statistik (BPS) meluncurkan keadaan angkatan kerja di Indonesia per Agustus 2019 (BPS, 2019). Keadaan angkatan kerja SMK memiliki tingkat pengangguran terbuka sebanyak 10,42\%, sedangkan SMA hanya memiliki tingkat pengagguran terbuka sebesar $7,92 \%$. Pertanyaan yang timbul adalah bagaimana SMK yang lulusannya memiliki keterampilan khusus, justru menyumbang angka pengangguran terbuka yang lebih banyak daripada SMA. 
Strategi khusus perlu dibuat agar tingkat pengangguran terbuka untuk lulusan SMK berkurang untuk tahun selanjutnya (Direktorat Pembinaan SMK, 2017). Pihak Direktorat Pembinaan SMK mengeluarkan strategi berupa membuat profil lulusan SMK yang diukur berdasarkan kognitif, afektif, dan psikomotorik. Profil tersebut dipetakan berdasarkan keterampilan untuk mendapatkan alternatif solusi pemecahan masalah tersebut. Strategi merupakan awal pondasi untuk meminimalisir tingkat pengangguran terbuka dari lulusan SMK. Strategi ini juga diharapkan mampu menyiapkan lulusan SMK agar mempunyai keterampilan sesuai dengan kebutuhan dunia usaha dan dunia insudtri.

Solusi lain yang diberikan oleh SMK untuk meminimalisir tingkat pengangguran terbuka dengan mencanangkan kegiatan wirausaha bagi lulusan SMK. Lulusan SMK pada dasarnya mempunyai kesempatan lebih tinggi untuk menentukan kondisi karirnya setelah menyelesaikan pendidikan. Lulusan SMK memiliki tiga peluang utama. Sebagian besar lulusannya dapat langsung bekerja, sebagian lagi dapat memilih untuk berwirausaha atau melanjutkan.

Solusi ini juga tertuang dalam revitalisasi lulusan SMK yang disusun BNSP SMK tahun 2016. Lulusan pendidikan kejuruan, khususnya SMK, didesain agar tidak sekadar fokus untuk berkerja saja, namun juga memiliki alternatif lain setelah lulus. Alternatif lain tersebut meliputi bekerja, melanjutkan, dan berwirausaha (BNSP, 2016). Lulusan SMK yang bekerja akan terlibat langsung dengan dunia usaha dan industri begitu lulus, sedangkan untuk yang memilih berwirausaha dapat membidik sasaran wirausaha mulai dari sektor industri kreatif. Kedua lulusan SMK yang memilih untuk bekerja maupun berwirausaha tidak dapat lepas dari kompetensi yang dibutuhkan dunia usaha dan dunia industri. Kompetensi yang dipelajari saat berada di bangku SMK sebaiknya tetap selarasa dengan kebutuhan masyarakat. Lulusan SMK yang berwirausaha dapat menjadi pendorong pertumbuhan industri serta ekonomi di Indonesia.

Kegitaan wirausaha di SMK perlu lebih ditingkatkan. Peserta didik perlu mendapatkan dukungan dari lingkungan sekitar, terutama pendidik untuk mengembangkan jiwa wirausaha individu. Peluang usaha bagi peserta didik SMK dirasa sangat besar karena SMK menekankan pada aspek keterampilan sebagai salan satu aspek penting yang perlu dikuasai. Hal tersebut dikarenakan aspek penilaian utama dalam pendidikan kejuruan adalah aspek keterampilan dari kompetensi yang diajarkan (Husna \& Sofyan, 2018). Kemampuan wirausaha perlu dididik sejak masih berada di bangku sekolah oleh para pendidik sebagai orang yang bertemu langsung dengan peserta didik di dalam kelas. Wirausaha yang dilalukan peserta didik dengan memanfaatkan teknologi dapat mengacu kepada technopreneurship.

Niat technopreneurship peserta didik dengan kinerja peserta didik saat praktikum dapat memiliki kaitan. Niat technopreneurship perlu dimiliki oleh lulusan SMK. Hal tersebut selaras dengan program pemerintah untuk menciptakan wirausaha baru. Direktur Jenderal Industri Kecil Menengah Kementerian Perindustrian, menargetkan penciptakan 20.000 wirausaha baru pada 2019 (Junianto, 2017). Program itu dimulai pada tahun 2017 dengan menargetkan penciptaan 5.000 wirausaha baru

Technopreneurship ialah gabungan dari kemampuan untuk menggunakan teknologi dan keterampilan kewirausahaan (Selvarani \& Venusamy, 2015). Technopreneurship merupakan sumber kekuatan ekonomi berdasar ilmu pengetahuan terbaru dengan memberdayakan sumber daya sehingga menghasilkan produk, keputusan yang tidak biasa, kompetisi yang agresif, manfaat inovasi dan teknologi, serta tanggungjawab terhadap resiko (Dutse, Ningi, \& Abubakar, 2013). Technopreneurship merupakan hasil inovasi dan kreativitas dari ilmu pengetahuan dan sintesis terhadap rekayasa teknis, baik secara 
individu atau kelompok (Musa et al., 2017). Technopreneurship sendiri merupakan sintesa kemampuan berwirausaha dengan teknologi dengan mendayagunakan sumber daya yang kreatif untuk berkompetisi dalam pasar usaha.

Technopreneur memiliki tugas mengumpulkan dan mengelola pengetahuan dan kemampuan untuk mendayagunakan sumber daya agar tujuan bisnis atau sosial tertentu dapat tercapai (Selvarani \& Venusamy, 2015). Technopreneur dapat merupakan seorang ilmuan atau insinyur yang memiliki sifat, keterampilan, dan pola pikir untuk berwirausaha dan mengomersialkan hasil mereka kepada masyarakat dan lingkungan luas (Wiradinata, 2014). Technopreneur adalah individu yang mendapatkan tantangan kemudian menciptakan solusi, melaksanakan solusi tersebut, dan bertindak. Seorang technopreneur di negara berkembang memiliki peluang cukup besar. Negara berkembang memiliki tantangan yang mampu dikembangkan untuk menjadi suatu usaha dengan memanfaatkan teknologi untuk alternatif solusi.

Perkembangan dunia usaha, khususnya di bidang industri berkaitan erat dengan technopreneurship (Dolatabadi \& Meigounpoory, 2013). Technopreneurship dilakukan dengan memanfaatkan kreativitas dari teknologi dan inovasi terbaru untuk mengembangkan bidang usaha secara komersil. Technopreneurship dapat difokuskan untuk membuat teknologi sehingga mampu digunakan untuk memperbesar peluang usaha yang inovatuf. Industri mengedepankan technopreneurship agar mampu bersaing seiring pertumbuhan tuntutan masyarakat.

Technopreneurship mempunyai dua aspek, yaitu aspek technopreneurship sebagai bagian dari teknologi dan aspek sebagai bagian dari wirausaha (Soegoto, 2010). Aspek tersebut berfungsi membuat teknologi bermanfaat bagi masyarakat mampu memberikan keuntungan bagi technopreneur. Menggunakan inovasi dari teknologi sehingga memiliki manfaat pada masyarakat merupakan fungsi technopreneurship ditinjau dari sisi teknologi. Keuntungan materi yang didapat dari pemanfaatan technopreneurship merupakan fungsi sisi wirausaha.

Karakter technopreneur memiliki tiga aspek utama penyusun, yaitu aspek intrapersonal, aspek interpersonal, dan aspek ekstrapersonal. Aspek technopreneurship tersebut berfokus pada pendayagunaan teknologi untuk mengembangkan bidang enterpreneurship. Jenis wirausaha pada technopreneurship tidak hanya berfokus untuk segi wirausaha teknologi informasi, tetapi semua unsur teknologi yang digunakan dan dapat menjadi pendukung dalam pengembangan wirausaha. Aspek-aspek yang membentuk seorang technopreneur adalah motivasi, kreativitas, manajemen, inovasi, kemandirian, dan kepemimpinan.

Technopreneurship merupakan salah satu bagian dari wirausaha yang mempunyai karakteristik tersendiri. Intelektual menjadi modal awal dari technopreurship (Byers, Dorf, \& Nelson, 2010). Intelektual memberikan pengaruh terhadap pengetahuan dan inovasi dari teknologi pada bidang usaha yang dijalani. Pengetahuan dan perkembangan teknologi dapat menentukan usaha tersebut berhasil atau gagal. Perusahaan dapat mengalami kemunduran apabila tidak mampu mengembangkan diri dalam bidang teknologi sesuai dengan perkembangan permintaan masyarakat.

Inovasi teknologi dan wirausaha memiliki kaitan erat dengan pertumbuhan ekonomi negara tertentu. Wirausaha yang mendayagunakan teknologi dapat menjadi pendorong dan pendukung penting untuk membangun ekonomi lokal dan nasional suatu negara (Lin et al., 2015). Ekonomi suatu wilayah dapat berkembang mulai dari sektor sektor usaha kecil dan menengah. Sektor usaha kecil dan menengah ini perlu memanfaatkan teknologi untuk memperluas pasar dan sebagai media untuk mempromosikan produk. 
Teknologi juga mampu membuat produsen skala kecil ini untuk bersaing dan mengembangkan usahanya dengan produsen lain atau produsen dengan skala yang lebih besar.

Seorang technopreneur harus memiliki sistem manajemen yang baik. Sistem manajemen yang terdapat dalam seorang technopreneur dibuat agar memberikan tindakan yang tepat. Seorang technopreneur mempunyai tiga hal yang dapat dilakukan untuk mengembangakan bidang usahanya, yaitu memproduksi produk yang tepat (right product), menghasilkan kualitas yang tepat (right quality), dan menentukan harga yang tepat (right price) (Hwa, 2009). Tiga hal tersebut harus diutamankan bagi seorang technopreneur untuk menentukan pasar yang akan dituju sesuai dengan tuntutan masyarakat. Kualitas produk yang dihasilkan juga sesuai dengan kriteria dan tuntutan pasar yang telah ditetapkan. Hal-hal itu akan menjaga kesesuaian standar kualitas dengan harga yang akan ditetapkan sesuai dengan kondisi pasar dan daya beli masyarakat.

Kegiatan technopreneurship tidak dapat dilepaskan kaitannya dengan niat sebagai awal penentu keinginan individu. Niat individu dihasilkan dari dua faktor utama, yaitu sikap terhadap perilaku dan norma subyektif (Baron \& Brancombe, 2012). Ada satu faktor lain yang juga memiliki kaitan erat dengan niat individu, yaitu persepsi kontrol perilaku (Ajzen, 2005; Hagger \& Chatzisarantis, 2008). Niat memiliki tiga indikator utama penyusun, yaitu sikap terhadap perilaku, norma subyektif, dan persepsi control perilaku.

Indikator penyususn niat ini dapat dilihat dari teori perilaku terencana. Niat pada teori perilaku terencana terdiri dari tiga indikator, yaitu: persepsi kontrol perilaku, norma subyektif, dan sikap. Ketiga indikator tersebut memiliki sub indikator yang dapat diuraikan lagi, seperti pada Gambar 1.

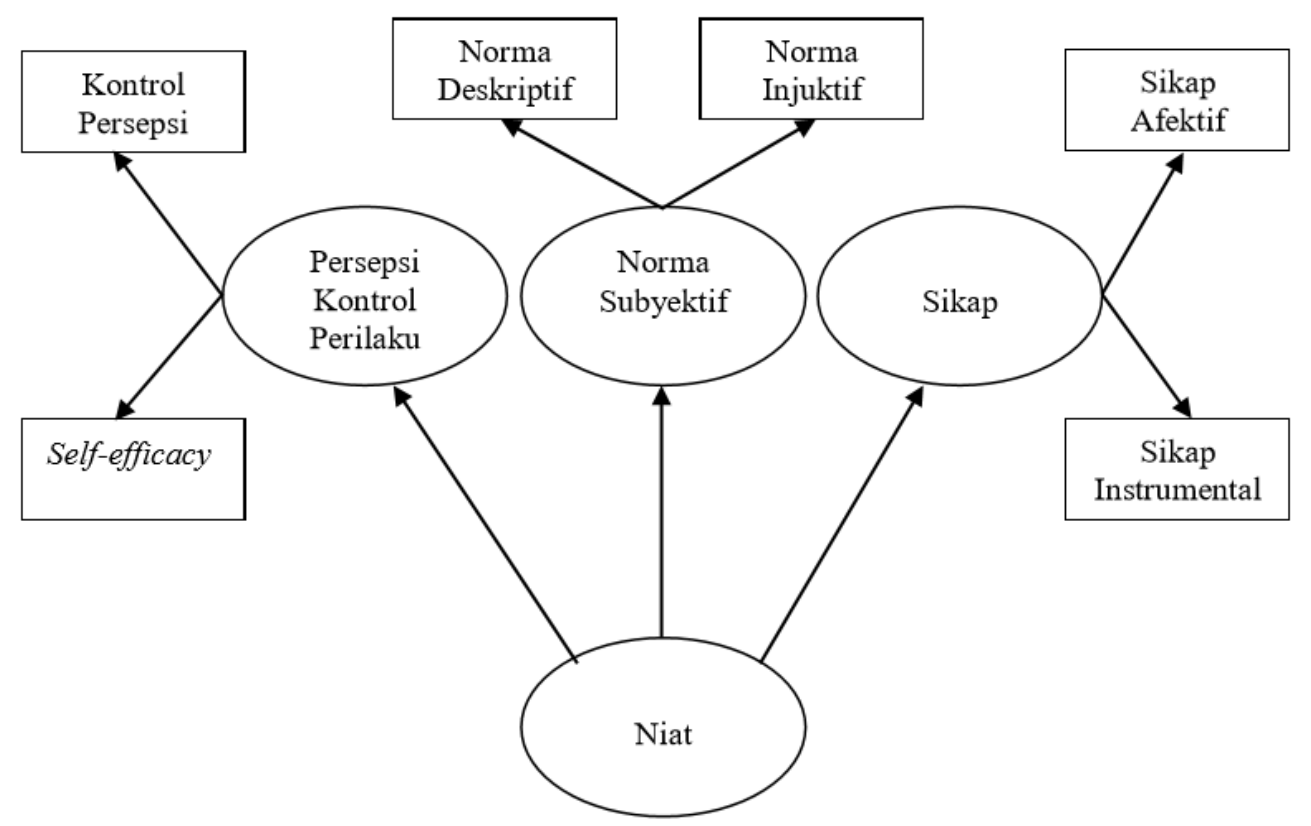

Gambar 1. Adaptasi Modifikasi Teori Perilaku Terencana (Hagger \& Chatzisarantis, 2008)

Gambar 1 menunjukkan sub indikator yang menyusun niat yang diadaptasi oleh Hagger \& Chatzisarantis (2008). Persepsi kontrol perilaku terdiri dari dua sub indikator, yaitu kontrol persepsi dan efikasi diri (self- efficacy). Kontrol persepsi merupakan kontrol seseorang individu dalam mengendalikan perilakunya masing-masing. Kontrol persepsi sendiri mampu diukur dengan dua faktor, yaitu kontrol keyakinan dan kuat persepsi (Montano \& Kasprzyk, 2008). Kontrol terhadap 
keyakinan memungkinkan seorang individu mampu mengukur faktor pendukung maupun faktor penghambat yang berada di dalam diri. Kuat persepsi individu dikendalikan oleh pengaruh dari keadaan individu yang mempengaruhi sulit atau tidak suatu pekerjaan atau kinerja. Efikasi diri ialah prediksi individu berkaitan dengan kemampuannya untuk melaksakan suatu perilaku. Norma subyektif terdiri dari dua komponen penyusun utama, yaitu norma deskriptif dan norma injuktif. Norma deskriptif memperlihatkan kondisi lingkungan sekitar yang memiliki dan melaksanakan perilaku yang sama. Norma injuktif memperlihatkan seberapa besar kondisi lingkungan sekitar mampu memberikan pengaruh terhadap perilaku tertendu pada individu. Sikap terhadap perilaku terdiri atas sikap afektif serta sikap instrumental. Sikap afektif mendeskripsikan keyakinan individu dari aspek emosi tentang tujuan yang diinginkan, seperti suka atau tidak suka. Sikap instrumental atau kognitif berhubungan erat dengan keyakinan individu tentang hasil yang ingin dituju, apakah hasil tersebut mampu memberikan dampak positif atau negatif, seperti perilaku individu yang mampu memberikan manfaat atau tidak.

Teori penyusun niat tersebut dapat dikembangkan untuk mengetahui apakah sesuai dengan faktor-faktor yang menyusun niat technopreneurship seorang peserta didik di SMK. Hal ini dilakukan agar pendidik dapat mengembangkan niat technopreneurship di SMK agar mampu menumbuhkan technopreneur baru di lingkungan pendidikan. Technopreneur tersebut diharapkan mampu untuk meningkatkan kualitas bidang wirausaha untuk mengembangkan sisi ekonomi di Indonesia.

\section{METODE}

Penelitian dilakukan melalui beberapa tahap, yaitu: pengajian teori dan observasi pra penelitian. Kajian teori dilaksanakan untuk mengembangkan definisi konsep niat technopreneurship di SMK yang telah dijabarkan oleh para ahli. Observasi pra penelitian bermanfaat untuk mengetahui kondisi dan kompetensi yang diberikan di SMK. Observasi ini juga berfungsi untuk mengetahui tujuan dari pembelajaran tersebut. Penjabaran dari definisi konsep dengan kompetensi yang diberikan di SMK disusun dan dikembangkan menjadi kisi-kisi instrumen penelitian.

Kisi-kisi intrumen niat technopreneurship di SMK yang dikembangkan berdasarkan pada definisi konsep dan observasi dapat dilihat pada Tabel 1.

Tabel 1. Kisi-kisi Instrumen Niat Technopreneurship

\begin{tabular}{|c|c|c|c|}
\hline Variabel & Indikator & $\begin{array}{c}\text { Sub } \\
\text { Indikator }\end{array}$ & $\begin{array}{c}\text { Jumlah } \\
\text { Item }\end{array}$ \\
\hline \multirow{8}{*}{$\begin{array}{c}\text { Niat } \\
\text { Techno- } \\
\text { preneurship }\end{array}$} & \multirow{3}{*}{$\begin{array}{l}\text { Sikap } \\
\text { Terhadap } \\
\text { Perilaku }\end{array}$} & Sikap afektif & 3 \\
\hline & & Sikap & 3 \\
\hline & & instrumental & \\
\hline & \multirow[t]{2}{*}{$\begin{array}{l}\text { Norma } \\
\text { Subyektif }\end{array}$} & $\begin{array}{l}\text { Norma } \\
\text { deskriptif }\end{array}$ & 3 \\
\hline & & $\begin{array}{l}\text { Norma } \\
\text { injuktif }\end{array}$ & 3 \\
\hline & \multirow{3}{*}{$\begin{array}{l}\text { Persepsi } \\
\text { Kontrol } \\
\text { Perilaku }\end{array}$} & Efikasi diri & 2 \\
\hline & & $\begin{array}{l}\text { Kontrol } \\
\text { keyakinan }\end{array}$ & 2 \\
\hline & & $\begin{array}{l}\text { Kuat } \\
\text { persepsi }\end{array}$ & 2 \\
\hline
\end{tabular}

Tahap selanjutnya adalah tahap uji pengembangan instrumen. Pengembangan instrumen dilakukan berdasarkan kisi-kisi penelitian yang sudah dilakukan. Instrumen yang dikembangkan adalah instrumen angket (self-assessment). Instrumen terdiri dari pengantar bagi subyek penelitian (peserta didik), petunjuk pengisian, contoh pengisian, serta item-item instrumen yang dikembangkan.

Tahap selanjutnya adalah peninjauan instrumen yang ada kepada para ahli. Para ahli akan memberikan saran terhadap item-item instrumen yang dikembangkan. Para ahli yang meninjau merupakan orang yang berkompeten dalam menghadapi peserta didik dan di bidang 
technopreneurship. Para ahli merupakan guru dan dosen di bidang pendidikan kejuruan.

Penelitian selanjutnya dilakukan dengan tahap uji coba terbatas. Uji coba terbatas dilaksanakan pada sejumlah 24 peserta didik. Uji coba terbatas dilaksanakan untuk mengembangkan instrumen yang disusun, sehingga menghasilkan butir-butir instrumen yang baik dan sesuai. Pelaksanaan uji coba terbatas dilakukan di SMK N 3 Yogyakarta.

\section{HASIL DAN PEMBAHASAN}

Peninjauan instrumen dari pada ahli mendapatkan beberapa saran dan masukan untuk pengembangan instrumen niat technopreneurship. Saran ini terkait dengan bentuk dan isi dari butir-butir instrumen yang dikembangkan dan dilaksanakan oleh peneliti untuk mendapatkan hasil lebih baik. Tahap selanjutnya adalah uji coba terbatas.

Hasil uji coba terbatas memperoleh beberapa data yang dianalisis validitas dan reliabilitanya. Instrumen penilaian niat technopreneurship bagi peserta didik dihitung melalui hasil korelasi skor butir terhadap skor total butir secara keseluruhan. Hasil dari validitas ini dapat mengetahui apakah setiap butir yang dikembangkan mampu mendukung hasil instrumen yang digunakan. Tabel 2 merupakan hasil validitas niat technopreneurship.

Tabel 2 menggambarkan hasil validitas niat technopreneurship. Uraian tersebut dapat disimpulkan dengan membandingkan skor $r_{\text {hitung }}$ dengan skor $r_{\text {tabel }}$. Skor $r_{\text {tabel }}$ yang digunakan sebagai patokan ialah 0,344 dengan nilai signifikansi 0,05 pada pengujian satu arah. Butir nomor 5, 11, dan 16 memiliki nilai $r_{\text {hitung }}$ kurang dari 0,344 . Hal tersebut menandakan bahwa butir tersebut digugurkan, sedangkan butir lain tetap dipertahankan.
Tabel 2. Ringkasan Statistik Validitas Niat Technopreneurship

\begin{tabular}{|c|c|c|}
\hline Indikator & $\begin{array}{c}\text { Nomor } \\
\text { pada } \\
\text { Instrumen }\end{array}$ & $\begin{array}{l}\text { Nilai } \mathbf{r} \\
\text { hitung }\end{array}$ \\
\hline \multirow{6}{*}{$\begin{array}{c}\text { Sikap Terhadap } \\
\text { Perilaku }\end{array}$} & 1 & 0,453 \\
\hline & 4 & 0,494 \\
\hline & 5 & 0,224 \\
\hline & 6 & 0,368 \\
\hline & 15 & 0,412 \\
\hline & 16 & 0,243 \\
\hline \multirow[t]{6}{*}{ Norma Subyektif } & 7 & 0,411 \\
\hline & 8 & 0,486 \\
\hline & 12 & 0,498 \\
\hline & 2 & 0,453 \\
\hline & 17 & 0,516 \\
\hline & 18 & 0,562 \\
\hline \multirow{6}{*}{$\begin{array}{l}\text { Persepsi Kontrol } \\
\text { Perilaku }\end{array}$} & 3 & 0,586 \\
\hline & 9 & 0,410 \\
\hline & 10 & 0,572 \\
\hline & 13 & 0,399 \\
\hline & 11 & 0,151 \\
\hline & 14 & 0,398 \\
\hline Jumlah & yang & igugurl \\
\hline
\end{tabular}

berdasarkan Tabel 2 adalah sejumlah 3 butir. Persebaran butir tersebut meliputi 2 item pada indicator sikap terhadap perilaku dan 1 item pada persepsi konstrol perilaku. Hal tersebut menunjukkan bahwa setiap sub indikator memiliki keterwakilan terhadap indikator sikap serhadap perilaku, norma subyektif, dan persepsi control perilaku. Setiap indikator pada butir instrument juga mendukung variabel niat technopreneurship.

Jumlah butir tersisa, yaitu 15 butir instrumen niat technopreneurship, dihitung untuk mendapatkan nilai reliabilitasnya. Perhitungan reliabilitas butir instrumen niat technopreneurship menggunakan reabilitas Alpha Cronbach. Perhitungan skor reliabilitas instrumen niat technopreneurship diukur pada setiap sub indikatornya. Instrumen niat technopreneurship terdiri dari tiga indikator, yaitu sikap terhadap perilaku, norma subyektif, dan persepsi kontrol perilaku. Hasil perhitungan reliabilitas niat technopreneurship terangkum pada Tabel 3. 
Tabel 3. Ringkasan Statistik Nilai Reliabilitas Niat Technopreneurship

\begin{tabular}{cccc}
\hline Item & $\begin{array}{c}\text { Jumlah } \\
\text { Item }\end{array}$ & $\begin{array}{c}\text { Nilai } \\
\text { alpha }\end{array}$ & Kategori \\
\hline $\begin{array}{c}\text { Niat } \\
\text { Techno- } \\
\text { preneurship }\end{array}$ & 15 & 0,814 & Tinggi \\
\hline $\begin{array}{c}\text { Sikap } \\
\text { Terhadap } \\
\text { Perilaku }\end{array}$ & 4 & 0,662 & Sedang \\
\hline $\begin{array}{c}\text { Norma } \\
\text { Subyektif }\end{array}$ & 6 & 0,737 & Sedang \\
\hline $\begin{array}{c}\text { Persepsi } \\
\text { Kontrol } \\
\text { Perilaku }\end{array}$ & 5 & 0,716 & Sedang \\
\hline
\end{tabular}

Tabel 3 menunjukkan bahwa nilai alpha pada variabel niat technopreneurship dan indikator sikap terhadap perilaku, norma subyektif, dan persepsi kontrol perilaku pada technopreneurship termasuk kategori reliabel. Kategori ini didapat karena nilai reliabilitas di atas 0,6 (Cicchetti, 1994).

Niat technopreneurship dapat diukur menggunakan tiga indikator yang difokuskan pada technopreneurship, yaitu sikap terhadap perilaku, norma subyektif, dan persepsi kontrol perilaku (Ajzen, 2005; Hagger \& Chatzisarantis, 2008). Hal tersebut juga sama dengan penelitian yang dilakukan Nguyen (2017). Penelitian tersebut membahas mengenai niat berwirausaha peserta didik. Niat berwirausaha peserta didik juga didukung oleh 3 indikator tersebut dan memberikan pengaruh terhadap perilaku individu.

Niat technopreneurship dapat diukur secara tidak langsung dengan beberapa sub indikator. Indikator subyek terhadap perilaku memiliki sub indikator sikap afektif dan sikap instrumental pada technopreneurship. Indikator norma subyektif memiliki sub indikator norma deskriptif dan norma injuktif. Indikator persepsi kontrol perilaku memiliki tiga sub indikator, yaitu efikasi diri, kontrol keyakinan, dan kuat persepsi.

Pengetahuan pendidik mengenai niat technopreneurship peserta didik mampu menjadi tolak ukur pendidik untuk memberikan bekal kepada peserta didik mengenai technopreneurship yang dapat dikembangkan. Pendidik dapat memberikan arahan dan bujukan kepada peserta didik yang memiliki niat technopreneurship agar mengembangkan dirinya. Pendidik juga mampu mendorong peserta didik untuk meningkatkan bidang technopreneurship masing-masing dengan bujukan. Bujukan tersebut dapat memberikan perubahan pada setiap individu. Terdapat dua macam bujukan, yaitu bujukan sistematis dan bujukan isyarat (Baron \& Branscombe, 2012). Bujukan sistematis menggunakan fungsi informasi pesan memiliki sifat struktural serta terkonsep. Bujukan sistematis mengandalkan seberapa kuat pesan yang dikirimkan. Bujukan isyarat tidak memfokuskan pada kuat informasi dari pesan tersebut, tetapi lebih menggunakan fungsi informasi yang mendukung. Informasi yang mendukung itu contonya siapa yang berbicara, keahlian yang dimiliki, serta lainnya.

\section{SIMPULAN}

Niat technopreneurship dapat diukur dengan menggunakan 15 butir instrumen. Masing-masing butir instrumen memiliki nilai validitas dan reliabitas yang sesuai. Nilai validitas untuk setiap butir soal berada di atas kategori yang ditentukan, yaitu $r_{\text {tabel }}$, sehingga dapat dikategorikan valid. Reliabilitas indikator penyusun niat technopreneurship berada di atas skor 0,60. Skor tersebut membuktikan bahwa item pada niat technopreneurship dikategorikan reliabel.

Niat technopreneurship dapat diukur menggunakan tiga indikator yang difokuskan pada technopreneurship, yaitu sikap terhadap perilaku, norma subyektif, dan persepsi kontrol perilaku. Indikator subyek terhadap perilaku memiliki sub indikator sikap afektif dan sikap instrumental pada technopreneurship. Indikator norma subyektif memiliki sub indikator norma deskriptif dan norma injuktif. Indikator persepsi kontrol perilaku memiliki tiga sub indikator, 
yaitu: efikasi diri, kontrol keyakinan, dan kuat persepsi.

\section{DAFTAR RUJUKAN}

Ajzen, I. (2005). Attitudes, Personality, and Behavior 2nd ed. New York: Open University Press.

Badan Pusat Statistik. (2017). Keadaan Angkatan Kerja di Indonesia: Labor Force Situation in Indonesia Agustus/August 2019. Jakarta: BPS $\mathrm{RI} /$ BPS-Statistics Indonesia.

Badan Standar Nasional Pendidikan. (2016). Kegiatan Uji Publik Pengembangan Standar Proses dan Standar Penilaian Pendidikan Menengah Kejuruan. Retrieved from http://www.bsnpindonesia.org/wp-content/uploads/2016 /12/PAPARAN-BSNP-PMK.pptx .

Baron, R.A. \& Branscombe, R.A. (2012). Social Psychology 13 ed. New Jersey: Pearson Education, Inc.

Byers, T.H., Dorf, R.C., \& Nelson, A.J. (2010). Technology Ventures From Idea to Enterprise. New York: The McGraw-Hill Companies, Inc.

Cicchetti, D.V. (1994). Guidelines, Criteria, and Rules of Thumb for Evaluating Normed and Standardized Assessment Instruments in Psychology. Psychological Assessment 1994, Vol 6, No 4, pp. 284-290. doi: 10.1037/10403590.6.4.284.

Direktorat Pembinaan SMK. (2017). Optimalisasi Pembelajaran di SMK untuk Menghasilkan Skilled Labor pada Era Masyarakat Ekonomi ASEAN (MEA). Direktorat Pembinaan Sekolah Menengah Kejuruan. Jakarta.

Dutse, A.Y., Ningi, S.I., \& Abubakar, S. (2013). Technopreneurship and Enterprise Growth in Nigeria: An Exploration into the Latent Role of Microfinance Banks. IOSR Journal of Business and Management (IOSR-JBM) Volume 12, Issue 2 (Jul. - Aug. 2013), PP 25-32.

Retrieved

from http://s3.amazonaws.com/academia.edu.d ocuments/32138469/E01222532.pdf?AW SAccessKeyId=AKIAIWOWYYGZ2Y5 3UL3A\&Expires $=1501652941 \&$ Signatur e=gpLGUmPdQfubK4HIIhLWq185Cdg

$\% 3 \mathrm{D} \&$ response-content-

disposition=inline $\% 3 \mathrm{~B} \% 20$ filename $\% 3 \mathrm{D}$ technopreneurship

_and_Enterprise_Growth.pdf.

Hagger, M.S. \& Chatzisarantis, N.L.D. (2008). Youth Attitudes. Dalam Smith, A.L. \& Biddle, S.J.H. (Eds). Youth physical activity and sedentary behavior: challenges and solutions. Illinois, USA: Human Kinetics.

Husna, A.F. \& Sofyan, H. (2018). Developing Electric Lighting Installation Practice Performance Instruments in Vocational High Schools. Journal of Physics: Conference Series. Retrieved from http://iopscience.iop.org/article/10.1088/ 1742-6596/1140/1/012012/pdf.

Hwa, C.E. (2009). An action learning journey of a technopreneur in rreating, Sustaining and growing a world class knowledgebased teaching organisation in factory automation in the 21st century. IMC Association DPhil by Explication. Jurnal. Retrieved from http://www.fasystems. com.sg/Chua\%20Eng\%20Hwa, \%20An\% 20Action\%20Learning\%20Journey\%20o f\%20a\%20Technopreneur.pdf.

Junianto, P.A. (2017). 2017, Pemerintah Target Ciptakan 5.000 Wirausaha Baru. Retrieved from https://money.kompas.com/read/2017/03/ 05/080000226/2017.pemerintah.target.ci ptakan.5.000.wirausaha.baru

Lin, L., Meng, L., Weizhong, Z., et al. (2015). Study on Technology Entrepreneurship Mode of Engineering College Students. International Journal of Simulation -Systems, Science \& Technology. 2015, Vol. 16 Issue 5B, p12.1-12.5. Diambil pada 3 Agustus 2017 dari http://ijssst.info/Vol-16/TIL/No5B/paper12.pdf.

Montano, D.E. \& Kasprzyk, D. (2008). Theory of Reasoned Action, Theory of Planned 
Behavior, and The Integrated Behavioral Model. Dalam Glanz, K., Rimer, B.K., \& Vismanath, K. (Eds). Health Behavior and Health Education 4th ed, Theory, Research, and Practice. San Francisco: Jossey-Bass.

Musa, H., Azmi, F.R., Mohamad, N., et al. (2017). Creative Industry Learning and Development Towards Craft Product: Critical Success Factors of Technopreneurship. Proceedings of Mechanical Engineering Research Day 2017, 246-247. Retrieved from https://www.researchgate.net/profile/ Haslinda_Musa/publication/317233074_ Creative_industry_learning_and_develop ment_towards_craft_product_Critical_su ccess_factors_of_technopreneurship/link s/592d3e050f7e9b83a996eb27/Creativeindustry-learning-and-developmenttowards-craft-product-Critical-successfactors-of-technopreneurship.pdf.

Nguyen, C. (2017). Entrepreneurial intention of international business students in Viet Nam: a survey of the country joining the Trans-Pacific Partnership. Journal of Innovation and Enterpreneurship.
Retrieved from https://innovationentrepreneurship.springeropen.com/articl es/10.1186/ s13731-017-0066-z;

Selvarani, A. \& Venusamy, K. (2015). A Study of Technopreneurship in Small and Medium Industry. Technopreneurship as a Firm Strategy: Links to Innovation, Creation and Performance. International Journal of Management (IJM). Retrieved from http://www.academia.edu/download/408 75790/A_STUDY_OF_TECHNOPREN EURSHIP_IN_SMALL_AND_MEDIU M_INDUSTRY-2-3.pdf.

Soegoto, E.S. (2010). Enterpreneurship Menjadi Pebisnis Ulung. Jakarta: PT Elex Media Komputindo.

Wiradinata, T. (2014). Insight From Technopreneurship Subjects: The Case of Informatics Engineering Departement. Proceeding International Conference on Enterpreneurship Education 2014, 87-94. Retrieved from http://dspace.uc.ac.id/bitstream/handle/12 3456789/934/RS1412053.pdf?sequence $=$ 5\&isAllowed=y. 